\title{
Nature of the Specific Anion Response of a Hydrophobic Weak Polyelectrolyte Brush Revealed by AFM Force Measurements
}

\author{
Joshua D. Willott, Timothy J. Murdoch, Grant B. Webber, and Erica J. Wanless* \\ Priority Research Centre for Advanced Particle Processing and Transport, University of Newcastle, Callaghan, NSW 2308, Australia
}

Supporting Information

ABSTRACT: Complementary interaction force measurements between an atomic force microscope (AFM) tip or colloid probe and a weak polybasic brush have been shown to yield a number of fundamental characteristics of the brush and its response to the presence of specific anions in aqueous solution. Stretching of the poly(2-diisopropylamino)ethyl methacrylate (PDPA) chains physisorbed to the AFM tip and modeling the resultant force curves allowed the persistence and contour lengths, molecular weight, and thus grafting density of the brush to be determined. In kosmotropic acetate, high osmotic forces associated with the swollen PDPA brush repelled the colloid probe during both approach and retraction. For mildly chaotropic nitrate the behavior was similar, but at high ionic strength and during retraction, the interaction was strongly adhesive partly because of decreased brush solvation. For strongly chaotropic thiocyanate, the interaction was adhesive over the entire concentration range studied. Here, physical contact between the poorly solvated brush and the colloid resulted in an attractive force.

\section{INTRODUCTION}

Stimuli-responsive surface coatings have attracted considerable attention owing to their diverse physicochemical behavior leading to a wide range of current and potential applications. ${ }^{1}$ One robust approach has been the fabrication of polymer brush-coated surfaces-assemblies of flexible polymer chains tethered by one end to a surface. ${ }^{2}$ Brush behavior is in part controlled by the chain grafting density $\sigma$, with $\sigma=s^{-2}$ where $s$ is the average distance between the end-tethered chains. ${ }^{3}$ At low grafting densities each end-tethered polymer chain is isolated from neighboring chains occupying a volume characterized by the free solution radius of gyration, $R_{\mathrm{g}}$, of a single grafted chain-the mushroom regime. As $\sigma$ increases the chains begin to overlap, and the resulting steric forces cause them to stretch normal to the substrate into the brush conformation. The transition between these two regimes is commonly discussed in terms of the reduced grafted density: $\Sigma$ $=\sigma \pi R_{\mathrm{g}}^{2}$, with $R_{\mathrm{g}}$ being dependent on the solvent quality. In theory, the mushroom-to-brush regime crossover occurs at $\Sigma=$ 1 , with real systems showing intermediate behavior up to $\Sigma=5$. $\Sigma$ is therefore a useful parameter for judging the brushlike character of a polymer film. ${ }^{3}$ One common class of responsive brushes are those prepared using $\mathrm{pH}$ - and salt-responsive annealed (weak) polyelectrolytes composed of weakly acidic or basic functional monomers. The fraction of charged monomer units along a weak polyelectrolyte chain varies as a function of environmental $\mathrm{pH}$ and ionic strength is dependent on the polymer's apparent $\mathrm{p} K_{\mathrm{a}}$ value. ${ }^{4}$ This ionizable behavior creates the distinction between weak and strong polyelectrolytes with

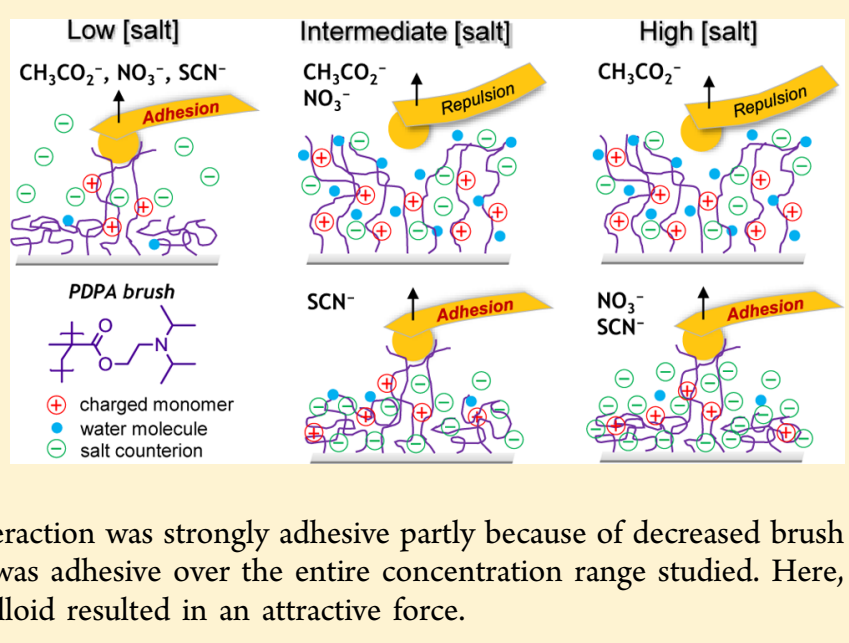

number and position of charged monomers fixed in the latter. Weak polyelectrolyte brushes can also be thermoresponsive. ${ }^{5-7}$ For all these reasons, weak polyelectrolytes are ideal polymers for the fabrication of stimuli-responsive surface coatings and have found use in, for example, protein adsorption, ${ }^{8}$ antimicrobial, ${ }^{9}$ and biosensing ${ }^{10}$ applications.

An important subclass of responsive brushes is that composed from weakly basic polymers. Typically, these brushes consist of polymers with monomer units containing a tertiary amine functional group including poly(2-vinylpyridine) $(\mathrm{P} 2 \mathrm{VP})^{11-13}$ and three poly(2-(dialkylamino)ethyl methacrylate) polymers: the 2-dimethylamino (PDMA),,$^{5-7,14-16} 2$ diethylamino (PDEA), ${ }^{15-18}$ and 2-diisopropylamino (PDPA) ${ }^{15,16,19,20}$ analogues. Weak polybasic brushes become protonated at $\mathrm{pH}$ values below their apparent $\mathrm{p} K_{\mathrm{a}}$ and the associated electrostatic repulsion between charged residues causes them to extend and swell via the uptake of solvent. While at higher $\mathrm{pH}$ values, hydrophobic interactions prevail as the polymer becomes uncharged and the brushes desolvate and collapse. $^{15}$

Brush response to solution ionic strength is considerably more complex. ${ }^{21-23}$ At very low ionic strengths, brush ionization is highly suppressed as the brush charging mechanism is down-regulated toward the uncharged state. Here the affinity of the substantially uncharged polymer for the

Received: December 7, 2015

Revised: February 12, 2016

Published: March 4, 2016 
solvent dictates brush conformation. ${ }^{16}$ Furthermore, the Debye screening length, $\kappa^{-1}$, is large, so electrostatic interactions are important. Gradually as more salt is added to solution additional salt counterions are taken up by the brush. This consequently reduces the electrostatic penalty imposed during brush charging as counterions assist in screening the charge; the local acid-base equilibrium shifts, allowing an increase of the charge within the brush. ${ }^{21}$ Each salt ion within the brush contributes on the order of $k_{\mathrm{B}} T$ to the osmotic pressure leading to an osmotic swelling of the brush via the concomitant uptake of water, known as the osmotic brush regime. Here brush height increases with salt concentration ${ }^{21}$ while also being dependent on the inherent hydrophobicity of the polymer. ${ }^{16,17}$ At a given solution ionic strength the brush reaches a maximum thickness and from thereon screening of the brush electrostatic charge by further increases in the amount of added salt becomes significant (i.e., decreasing values of $\kappa^{-1}$ ) 一the salted brush regime. As the hydrophobic polymer-polymer interactions begin to dominate the diminished electrostatic repulsive and hence osmotic swelling forces, brush height decreases as the polymer chains collapse. The salt-responsive behavior of weak polyelectrolyte brushes was initially predicted in theories developed by Israëls et al. ${ }^{24}$ and Zhulina and co-workers ${ }^{25,26}$ with expansions on their seminal works published since. ${ }^{21-23}$ These predictions have been supported by experimental work on the salt response of weak polyacid brushes ${ }^{27-30}$ as well as for a range of weak polybasic brushes. ${ }^{16,17}$

Previously, we have reported on the ionic strength dependent and anion-specific behavior of three weak polybasic tertiary amine methacrylate brushes of increasing inherent polymer hydrophobicity, PDMA, PDEA, and PDPA, respectively. ${ }^{16}$ These experiments were performed at constant $\mathrm{pH}$, where the brushes were fully swollen at intermediate salt concentrations. Ellipsometry and quartz crystal microbalance with dissipation monitoring measurements showed that weak polybasic brush solvation, conformation, and viscoelasticity varied not only with ionic strength, as suggested by theory, but also with the identity of the salt anion with potassium acetate, nitrate, and thiocyanate studied. These anions reside at different locations within the well-known Hofmeister series.

Ion-specific or Hofmeister effects are ubiquitous in soft matter and biological systems and concern phenomena that are dependent on not only the concentration but also the identity of added salt. ${ }^{31,32}$ Anions typically exhibit stronger effects than cations due to their greater range in ion polarizability. ${ }^{32}$ Hofmeister series ions are historically classified based on their kosmotropic or chaotropic nature, which defines their location within the series. Kosmotropic ions (kosmotropes) are characterized by their strong hydration and high charge density $^{32,33}$ whereas chaotropic ions (chaotropes) are more charge-diffuse ions ${ }^{32}$ and are weakly hydrated. ${ }^{32-34}$ Chaotropes have been shown to partition favorably toward the air-water interface ${ }^{35,36}$ as well as toward poorly hydrated or hydrophobic surfaces, ${ }^{37-40}$ with a strong correlation between their relative affinities and the ion's position within the Hofmeister series. ${ }^{36,41}$ In our previous study, ${ }^{16}$ kosmotropic acetate anions exhibited low affinity for the weak polybasic brushes in the salted brush regime, meaning that the brushes remained highly solvated and in an extended conformation toward high acetate concentrations. Significantly, the mildly chaotropic nitrate and strongly chaotropic thiocyanate anions showed a polymer hydrophobicity-dependent affinity for the brushes. The three weak polybasic brushes collapsed at higher ionic strengths due to the increased screening of the repulsive electrostatic interactions and possible ion-polymer specific interactions with the response being most pronounced for the most hydrophobic (PDPA) brush.

In situ force measurements of polyelectrolyte brush-coated surfaces can provide insight into brush conformation, thickness, and physicochemical properties like interfacial adhesion and lubricity, all as a function of environmental conditions like $\mathrm{pH}$ and ionic strength, with surface force apparatus, ${ }^{42-44}$ surface force balance, ${ }^{45,46}$ optical tweezers, ${ }^{47-49}$ and most commonly sharp tip ${ }^{50-52}$ and colloidal probe pric $^{11-13,53-56}$ atomic force microscopy (AFM) measurements reported. When two identical polyelectrolyte brush surfaces are brought close together they repel each other, and the range of these repulsive predominantly steric but also electrostatic forces reveals information about brush thickness, charge, and conformation at varying environmental conditions. ${ }^{4-46,54}$ For potential applications like particle stabilization, molecular binding, and biosensing, understanding the interaction forces between polyelectrolyte brushes and dissimilar colloidal bodies is of great importance. Recently, the interaction of unmodified silica microparticles with both strong and weak polyelectrolyte brushes has revealed that both attractive and repulsive forces exist between the two, dependent on the $\mathrm{pH}$ and ionic strength of the surrounding medium. ${ }^{11-13,53,56}$

Herein we present in situ AFM force measurements between a silica-colloid probe and a hydrophobic, weakly basic PDPA brush at $\mathrm{pH} 4.5$ as a function of a range of potassium acetate, nitrate, and thiocyanate electrolyte solutions with overall ionic strength values between 0.04 and $100 \mathrm{mM}\left(4 \times 10^{-5}\right.$ and 0.1 $\mathrm{M})$. These measurements were performed at $\sim 1.5$ units below the apparent $\mathrm{pK}$ a of the PDPA brush where the brush is significantly swollen at intermediate salt concentrations. ${ }^{15,16}$ The force-distance curves upon approach of the colloid toward the brush surface are quantitatively modeled using the Alexander-de Gennes (AdG) and Milner-Witten-Cates (MWC) polymer brush theories to obtain insight into the influence of ionic strength and salt identity on overall brush thickness. Analysis of the retraction data gave the energy dissipated by the brush during each approach-retraction cycle as well as an understanding of the adhesive properties of the brush in the presence of specific anions. We also present singlemolecule force spectroscopy measurements of a solvated PDPA brush using an AFM tip which allowed for physical quantification of chain persistence and contour lengths together with brush molecular weight and hence grafting density, comparing this value to the grafting density values obtained from the AdG and MWC fitting.

\section{MATERIALS AND EXPERIMENTAL METHODS}

Materials. Silicon wafers with a native oxide layer were purchased from Silicon Valley Microelectronics, Santa Clara, CA. Surface-bound initiator functionalization reagents including (3-aminopropyl)triethoxysilane (APTES), $\alpha$-bromoisobutyryl bromide (BIBB), triethylamine $\left(\mathrm{Et}_{3} \mathrm{~N}\right)$, and tetrahydrofuran $(\mathrm{THF})$ were purchased from Sigma-Aldrich. The tetrahydrofuran was dried over $4 \AA$ molecular sieves before use (for at least 1 day). 2-(Diisopropylamino)ethyl methacrylate (DPA) monomer was purchased from Sigma-Aldrich. The monomethyl ether hydroquinone inhibitor was removed from the DPA monomer immediately prior to use by gravity feeding the monomer through a $10 \mathrm{~cm}$ high by $2 \mathrm{~cm}$ diameter alumina, activated basic, column. Polymerization reagents including copper(II) bromide $\left(\mathrm{CuBr}_{2}, 99.999 \%\right), 2,2^{\prime}$-bipydridine (bipy, $\left.\geq 99 \%\right)$, and L-ascorbic acid $(\geq 99 \%)$ were purchased from Sigma-Aldrich and used as received. 
Polymerization solvent isopropyl alcohol (IPA, 99.7\%) was purchased from Chem-Supply Pty Ltd. and used as received. Measurements were performed in potassium nitrate $\left(\mathrm{KNO}_{3}\right.$, Asia Pacific Specialty Chemicals Ltd. Pty., >99\%), potassium acetate $\left(\mathrm{KCH}_{3} \mathrm{CO}_{2}\right.$, Alfa Aesar, $>99 \%$ ), and potassium thiocyanate (KSCN, Alfa Aesar, >98\%) electrolyte solutions in the concentration range of $0.01-100 \mathrm{mM}$. Solution $\mathrm{pH}$ was controlled at the desired value $(\mathrm{pH} 4.5$ for all colloid probe experiments), accurate to within \pm 0.1 of a $\mathrm{pH}$ unit. For the $\mathrm{pH}$ adjustments of the nitrate and thiocyanate solutions a minimum amount of $10 \mathrm{mM}$ nitric acid (RCI Labscan Ltd.) or potassium hydroxide (Chem-Supply Ltd. Pty., >99\%) was used. For the acetate electrolyte solutions, acetic acid was used for the $\mathrm{pH}$ adjustments. Milli-Q water $\left(18.2 \mathrm{M} \Omega \cdot \mathrm{cm}\right.$ at $25^{\circ} \mathrm{C}$, Millipore) was used throughout.

Surface Preparation and Brush Synthesis. The wafer surfaces were prepared for brush synthesis following our established protocol. ${ }^{15-17}$ Briefly, oxidized silicon wafers were cleaned by UV/ $\mathrm{O}_{3}$ treatment for $20 \mathrm{~min}$ (Bioforce $\mathrm{UV} / \mathrm{O}_{3}$ cleaner, $\sim 9 \mathrm{~mW} \mathrm{~cm}{ }^{-2}$ at $254 \mathrm{~nm}$ ), followed by sonication in Milli-Q water for $15 \mathrm{~min}$ with the water replaced at $5 \mathrm{~min}$ intervals. The wafers were then immersed in $10 \mathrm{wt} \%$ sodium hydroxide for $30 \mathrm{~s}$ before being rinsed with copious amounts of Milli- $Q$ water and dried with nitrogen gas. Cleaned wafers were then amine-functionalized by exposure to APTES vapor at $<5$ mbar vacuum pressure for $30 \mathrm{~min}$ at room temperature $\left(23^{\circ} \mathrm{C}\right)$ before the APTES monolayer was annealed in air at $110^{\circ} \mathrm{C}$. The aminefunctionalized wafers were subsequently reacted with a solution of BIBB $(0.26 \mathrm{~mL}), \mathrm{Et}_{3} \mathrm{~N}(0.3 \mathrm{~mL})$, and THF $(10 \mathrm{~mL})$ for $60 \mathrm{~min}$ at room temperature, converting the amine moieties to bromine initiator moieties. Poly(2-diisopropylamino)ethyl methacrylate (PDPA) brushes were synthesized from the bromine-initiator-functionalized wafers following an established surface-initiated activators regenerated by electron transfer atom transfer radical polymerization (ARGET ATRP) methodology. ${ }^{15-17}$ Brush polymerization was carried out in a solvent mixture of IPA/ $\mathrm{H}_{2} \mathrm{O}$ at 9:1 v/v using an ARGET ATRP recipe composed of DPA/ $\mathrm{CuBr}_{2} /$ bipy/ascorbic acid in the molar ratios of $2500 / 1 / 10 / 10 . \mathrm{CuBr}_{2}$ was the catalyst, bipy was the ligand, and ascorbic acid was the reducing agent. The ratio of solvent mixture to DPA monomer was 1:1 v/v. For more detailed synthetic steps please see the Supporting Information.

Dry Ellipsometry. Dry brush thickness measurements were performed using a Nanofilm EP3 single wavelength $(532 \mathrm{~nm}$ green laser) imaging ellipsometer controlled using EP3View software. The ellipsometric parameters $\psi$ and $\Delta$ were modeled using WVASE software based on the following optical model: a $1 \mathrm{~mm}$ (optically infinite) silicon layer topped by a $1.8 \mathrm{~nm}$ (measured) silica layer then an uppermost PDPA brush layer, with the thickness of the brush layer the only unknown parameter. The values for the real $n$ and imaginary $k$ components of the refractive indices of each material were $n=4.15, k$ $=0.0439$ for silicon, $n=1.461, k=0$ for silica, and $n=1.517, k=0$ for PDPA. Measurements were made at three angles of incidence $\left(60^{\circ}\right.$, $50^{\circ}$, and $42^{\circ}$ ) and reported dry brush thickness measurements are an average of three measurements made at three distinct locations on the wafer surface. The dry brush thickness values for the PDPA brushes studied are given in Table 1.

Surface Zeta Potential. A Malvern Zetasizer Nano ZSP instrument equipped with a Malvern surface zeta potential cell was used to determine the surface zeta potential of an oxidized silicon wafer, an APTES-functionalized, initiator-functionalized, and PDPA brush-coated surface. The measurements were performed at $23{ }^{\circ} \mathrm{C}$ in

Table 1. Dry Brush Thickness Values for the PDPA Brushes Studied

\begin{tabular}{lc}
\multicolumn{1}{c}{ AFM experiment } & $\begin{array}{c}\text { ellipsometric dry brush thickness } \\
(\mathrm{nm})^{a}\end{array}$ \\
$\begin{array}{l}\text { single-molecule force spectroscopy } \\
\text { study }\end{array}$ & $18.0 \pm 0.6$ \\
$\begin{array}{c}\text { ionic strength and specific ion study } \\
\text { ind }\end{array}$ & $11.0 \pm 0.5$
\end{tabular}

${ }^{a}$ Uncertainties are the standard deviation from multiple, distinct measurement areas on the wafer. the presence of $0.01 \mathrm{mM} \mathrm{KNO}_{3}$ electrolyte adjusted to $\mathrm{pH} 4.5$ using dilute nitric acid (making the ionic strength of the solution $0.04 \mathrm{mM}$ ). Reported values and uncertainties are the average of at least two individual measurements. The tracer particles used were either silica particles $(\sim 120 \mathrm{~nm},-27.3 \pm 2.1 \mathrm{mV})$, for the negatively charged surfaces, or alumina particles $(\sim 50 \mathrm{~nm},+30.0 \pm 3.2 \mathrm{mV})$, for the positively charged surfaces. At high salt concentrations the tracer particles aggregated, and this together with increased brush swelling and charging made these surface zeta potential measurements difficult.

In Situ Atomic Force Microscopy. Normal force measurements were performed using a Bruker Multimode VIII AFM with a vertical engage EV scanner in contact mode equipped with a closed fluid cell at $23 \pm 2{ }^{\circ} \mathrm{C}$ (Bruker, USA). Single-molecule force spectroscopy measurements were performed using a $\mathrm{V}$-shaped silicon nitride cantilever with a manufacturer quoted tip radius of $20 \mathrm{~nm}$ and a reflective gold-coating on the backside (DNP-10, Bruker, USA). The colloid probe was prepared by gluing (using a two-component epoxy resin) a single, dry native silica microsphere (Bangs Laboratories Inc., USA, diameter $4.7 \mu \mathrm{m}$ as measured using a Zeiss Axioskop 40 light microscope) onto a tipless rectangular silicon nitride cantilever with a backside coating of aluminum (HQ:NSC36/tipless/Al BS, Mikromasch, USA). The spring constant (an average of five discrete measurements) of the two cantilevers used was determined via the built-in thermal noise method. A $0.08 \mathrm{~N} \mathrm{~m}^{-1}$ spring constant cantilever was used for the single-molecule force spectroscopy (SMFS) measurements, and a $1.86 \mathrm{~N} \mathrm{~m}^{-1}$ spring constant cantilever was used for the colloid probe normal force measurements. For the colloid probe, the spring constant was measured before gluing of the silica microsphere. Immediately prior to in situ measurements, the fluid cell and O-ring were cleaned by careful rinsing with ethanol and Milli-Q water and drying under nitrogen. Cantilevers were cleaned by thorough rinsing with ethanol and Milli-Q water before being dried with nitrogen; afterward, the SMFS cantilever was exposed to UV/O for 15 min. Before any in situ measurements, the PDPA brush samples were hydrated in $\mathrm{pH} 4.0,10 \mathrm{mM} \mathrm{KNO}_{3}$ electrolyte for at least $60 \mathrm{~min}$. After mounting of the gently dried (by nitrogen) brush sample and appropriate cantilever, the AFM fluid cell was filled with the desired electrolyte solution, being careful to remove all air bubbles. Between each environmental condition $10-15 \mathrm{~mL}$ of the new electrolyte solution was flowed through the fluid cell. The brushes were allowed to equilibrate in the desired electrolyte solution for at least $15 \mathrm{~min}$ before any force measurements were performed. Our studies revealed that this equilibration time was sufficient, with no drift observed in the measured force curves over time. The colloid probe measurements were performed over approximately $12 \mathrm{~h}$ with the PDPA brush immersed in solution throughout. Cantilever deflection vs displacement data of the resultant force curves were converted to normal force vs apparent separation curves using standard methods as outlined by Ralston et al. ${ }^{57}$

Single-Molecule Force Spectroscopy (SMFS) Study. SMFS measurements were performed on a PDPA brush with a dry thickness of $18.0 \pm 0.6 \mathrm{~nm}$. These experiments were made in $10 \mathrm{mM} \mathrm{KNO}_{3}$ electrolyte solutions at $\mathrm{pH}$ values of 5.5, 5.0, and 4.0. The force measurements were performed over a ramp size of $600 \mathrm{~nm}$, at a tip velocity of $500 \mathrm{~nm} \mathrm{~s}^{-1}$, with no surface dwell and at a constant maximum indentation load (trigger threshold: the maximum force applied to the brush sample), which was set sufficiently high that the region of constant compliance was reached for all environmental conditions. In our previous work, quartz crystal microbalance measurements have shown that a PDPA brush is in its most solvated, extended conformation at $\mathrm{pH}$ values $\leq 5 .{ }^{15}$ Consequently, these conditions provide the best chance to stretch (i.e., interact with) individual polymer chains. On approach the tip penetrated the brush until the trigger threshold was reached. During tip retraction from within the swollen brush ideally single chains, but more likely multiple chains adhere to the tip, stretch, and then detach from the tip. The corresponding force as a function of separation distance was recorded. Force measurements were repeated at various locations on the brush surface, covering an area of $0.75 \mu \mathrm{m}$ by $0.75 \mu \mathrm{m}$. For each $\mathrm{pH}$ condition at least 450 single force-distance curves were obtained. The 
elastic behavior of a stretched single chain can be well-described by the wormlike chain (WLC) model in which the force, $F_{\text {chain }}$, to stretch a polymer chain characterized by its persistence length $L_{\mathrm{p}}$ and contour length $L_{\mathcal{C}}$ to an end-to-end distance $x$ in a solvent is defined as ${ }^{58}$

$$
F_{\text {chain }}=\frac{k_{\mathrm{B}} T}{L_{\mathrm{p}}}\left(\frac{x}{L_{\mathrm{c}}}-\frac{1}{4\left(1-\frac{x}{L_{\mathrm{c}}}\right)^{2}}-\frac{1}{4}\right)
$$

where $k_{\mathrm{B}}$ is the Boltzmann constant and $T$ is the absolute temperature. To best evaluate the molecular weight of the brush, only the final detachment event for each retraction curve was analyzed as this represented the highest probability for stretching of a single chain. The value of $x$ at the point of detachment is referred to as $x_{\max }$ the maximum chain extension. These final detachment events were fitted to the WLC model with $L_{\mathrm{p}}$ and $L_{\mathrm{c}}$ as free parameters in the fit using a custom Matlab script. It was assumed that the tip penetrated very close to the substrate such that $x \sim D, 59,60$ where $D$ is the surface separation. Fits were constrained such that $x<L_{\mathrm{c}}$. Fits with a high mean-square error, low number of data points $(<10)$, or a fitted persistence length less than the length of the monomer unit were rejected from statistical analysis. A low fitted persistence length typically corresponded to fits with deep attractive minima $(<\sim-0.35 \mathrm{nN})$. This suggested multiple chains of similar $L_{\mathrm{c}}$ were stretched by the tip. Examples of the types of curves included and excluded from the analysis are discussed and are discussed in more detail later. From the distribution of measured contour lengths the molecular weight, $M_{i}$, can be determined using

$$
M_{i}=\frac{M_{0} L_{\mathrm{c}}}{a}
$$

where $M_{0}$ is the monomer molar mass $\left(213 \mathrm{~g} \mathrm{~mol}^{-1}\right.$ for DPA $)$ and $a$ is the length of the monomer unit $(0.30 \mathrm{~nm}$ which is calculated based on the projected $\mathrm{C}-\mathrm{C}$ bond lengths in the DPA monomer). The grafting density can be calculated by

$$
\sigma=\frac{h_{\mathrm{d}} \rho N_{\mathrm{A}}}{M_{i}}
$$

where $h_{\mathrm{d}}$ is the measured dry brush thickness, $\rho$ is the estimated polymer density $\left(1.035 \mathrm{~g} \mathrm{~cm}^{-3}\right)$, and $N_{\mathrm{A}}$ is Avogadro's number. As the polymer chains are significantly swollen and should also be highly charged at the chosen solution conditions (low $\mathrm{pH}$ at intermediate salt concentration), their radius of gyration, $R_{g}$, when in a good solvent is given by ${ }^{61}$

$$
R_{\mathrm{g}} \sim \frac{N_{\mathrm{p}}{ }^{3 / 5}}{\sqrt{6}}
$$

where $N_{\mathrm{p}}$ is the number of statistical chain segments $\left(L_{\mathrm{c}} / L_{\mathrm{p}}\right)$. This allows the calculation of the reduced grafting density $\Sigma$, where $\Sigma=$ $\pi \sigma R_{\mathrm{g}}^{2}$.

Ionic Strength and Specific lon Study. These force measurements were performed on an $11.0 \pm 0.5 \mathrm{~nm}$ dry thickness PDPA brush using the colloid probe AFM technique. Overall 15 different electrolyte conditions were studied: $\mathrm{KNO}_{3}, \mathrm{KCH}_{3} \mathrm{CO}_{2}$, and $\mathrm{KSCN}$ solutions with concentrations of $0.01,0.1,1,10$, and $100 \mathrm{mM}$ at controlled $\mathrm{pH}$ of 4.5 \pm 0.1 . Because of the $\mathrm{pH}$ adjustment to 4.5 , the ionic strength of the solutions was $\sim 0.03 \mathrm{mM}$ higher. This is only significant at low salt concentrations, i.e., at 0.01 and $0.1 \mathrm{mM}$, becoming negligible for the higher concentrations. Where possible, the anion released by the acid and anion in solution were matched. For example, the $\mathrm{KNO}_{3}$ solutions were actually 0.01 and $0.1 \mathrm{mM} \mathrm{KNO}_{3}$ with an additional $0.03 \mathrm{mM}$ $\mathrm{HNO}_{3}$, corresponding to an ionic strength of 0.04 and $0.13 \mathrm{mM}$. For safety reasons, the KSCN solutions were $\mathrm{pH}$ adjusted with nitric acid. Additionally, at such low ionic strengths, trace quantities of salt are often present which would result in a slight increase the overall solution ionic strength. Force measurements were performed from low to high ionic strength in the order of $\mathrm{KNO}_{3}, \mathrm{KCH}_{3} \mathrm{CO}_{2}$, and then KSCN. When changing between salt types, $15 \mathrm{~mL}$ of Milli-Q water was flowed slowly through the fluid cell before the new electrolyte solution was injected. Force-distance curves were obtained over a ramp size of $500 \mathrm{~nm}$, at a tip velocity of $500 \mathrm{~nm} \mathrm{~s}^{-1}$ during both approach and retraction, with no surface dwell and at a constant trigger threshold (chosen so that constant compliance was reached for all environmental conditions). A total of 25 curves were collected at each condition. Average approach and retraction curves were determined using a custom MATLAB script. First, curves were linearly interpolated in $0.05 \mathrm{~nm}$ increments such that the $n$th point of each curve corresponded to the same apparent separation value. Average and standard deviation values were then determined at each separation and were found to be highly reproducible. The most representative curve was then chosen for plotting, which was the curve with the smallest squared error compared to the generated average curve (see Figure 1 for an example). The energy dissipated by the system during

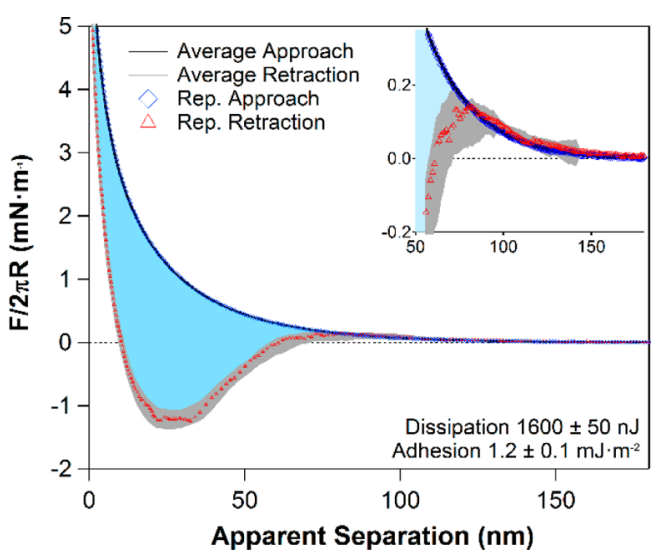

Figure 1. Average approach (black) and retraction (gray) curves (from 25 measured curves) with overlaid most representative curves (blue diamonds and red triangles, respectively), for a PDPA brush and the selected $0.04 \mathrm{mM}$ potassium nitrate case. The black and gray curves correspond to 2 standard deviations from the interpolated average curve; for a normal distribution this corresponds to about $95 \%$ confidence. The inset plot highlights the region over which the dominant adhesive force observed during retraction becomes repulsive and overlays the approach data toward larger separations.

each cycle was calculated by trapezoidal integration of the area between corresponding interpolated approach and retraction curves. ${ }^{62}$ The minimum of each retraction curve was also determined and corresponds to the maximum adhesion force.

For soft surfaces like swollen brushes, the region of constant compliance essentially corresponds to a layer of compressed polymer and not zero surface separation as is the case for contact between two incompressible surfaces. The thickness of this compressed layer could not be determined within the experimental design but could be estimated by fitting the approach component of the force-distance curves using the Alexander-de Gennes (AdG) and Milner-WittenCates (MWC) neutral polymer brush models (described below). This is possible as these fits go to infinity as the surface separation approaches zero, and so inevitably an offset value exists between the theoretical and measured force curves that reflects the true surface separation. This fitting procedure resulted in a horizontal shift of the force-distance curves known as the $D_{\text {offset }}$ which was dependent on the solution environment in which the brush was immersed. This distance also depends on the stiffness of the cantilever, and since a quite stiff cantilever (high spring constant, $\sim 2 \mathrm{~N} \mathrm{~m}^{-1}$ ) was used in this study, the brush was compressed close to its dry thickness.

The Alexander-de Gennes ${ }^{63}$ and Milner-Witten-Cates ${ }^{64}$ polymer brush theories were developed to describe the repulsive steric force acting between two identical uncharged polymer brushes as they approach each other. By employing a slight variation to the original theories highlighted by O'Shea et al. ${ }^{65}$ and using the Derjaguin approximation, the geometry-independent interaction force between a brush and colloid probe can be modeled (eqs S5 and S6 for AdG and 
MWC models, respectively). Both the AdG and MWC force profiles can be well approximated at intermediate surface separations by an exponential function with a characteristic decay length which reflects the range of the steric repulsive interactions. The decay lengths were determined by fitting eq $\mathrm{S} 7$ to each approach curve. For further details on these theories and the exponential modeling please refer to the Supporting Information. Even though these theories are for neutral (uncharged) brushes and so do not consider long-range electrostatic interactions, they can be approximately applied to polyelectrolyte brushes. This is because under certain solution conditions the brush charge is substantially screened by confined (adsorbed) counterions that reside in the vicinity of the brush, i.e., at higher ionic strengths, hence low Debye lengths, where the spatial range of the electrostatic interactions is small. ${ }^{2}{ }^{P}$

The AdG, MWC, and exponential fits were implemented in MATLAB for every approach curve using the trust-region-reflective algorithm to minimize the mean-squared error. Confidence intervals of 95\% were extracted from the Jacobian. The SMFS analysis was used to fix $L_{\mathrm{p}}$ and provide initial estimates for $L_{\mathrm{c}}$ and $\sigma$. At a fixed grafting density the contour length scales linearly with degree of polymerization and hence dry brush thickness. Fitting was performed for data between 5 and $50 \%$ of the maximum measured force. As discussed earlier, $D_{\text {offset }}$ was used as a fit parameter to convert apparent separation to an estimated true surface separation, $D$. Values for $D_{\text {offset }}$ used to produce the presented curves are taken from the MWC fitting as these fits had, overall, the lowest mean-squared error.

\section{RESULTS AND DISCUSSION}

Single-Molecule Force Spectroscopy Measurements. For polymer brushes prepared via surface-initiated polymerizations on planar substrates, quantifying polymer molecular weight and hence grafting density is a considerable challenge. Direct characterization through gel permeation chromatography of the cleaved polymer is often inaccurate due to the low amount of recoverable polymer. ${ }^{66}$ Indirect quantification of molecular weight by measuring free polymer synthesized simultaneously in the bulk is unsuitable since the polymerization conditions in the bulk are generally substantially different to those experienced during a surface-initiated polymerization. ${ }^{67}$ Advances in AFM-based high resolution single-molecule force spectroscopy (SMFS) have demonstrated the capacity to accurately measure brush molecular weight under appropriate conditions. ${ }^{59,60,68-70}$ This measurement involves the stretching of multiple (or ideally individual) polymer chains, which physisorb to the AFM tip, away from the substrate. Contour length and persistence length are estimated from the chain stretching events through application of the wormlike chain model (eq 1).

In this study, the retraction component of the force-distance curves were rigorously analyzed to ensure the results have high statistical significance. Figure 2a shows a typical retraction curve. Multiple attractive force peaks, arising from chain stretching, were observed in the single retraction cycle. Figure $2 \mathrm{~b}$ presents the wormlike chain fit of the final detachment event for the same data on a smaller $y$-axis scale. To avoid complexities associated with multiple chain pull-offs, we only consider the final chain stretching events. Here, only those pulloffs in which the attractive force returns to zero force, the baseline, after detachment of the measured chain were considered. This situation best reflects the stretching of a single chain. ${ }^{59}$ Fitted values of $L_{p}$ smaller than the length of monomer unit $(0.30 \mathrm{~nm})$ were rejected as being physically unrealistic. These correlated with adhesion forces greater than $\sim 0.35 \mathrm{nN}$, which were not observed with physically reasonable fits. The large attractive forces are most likely the result of

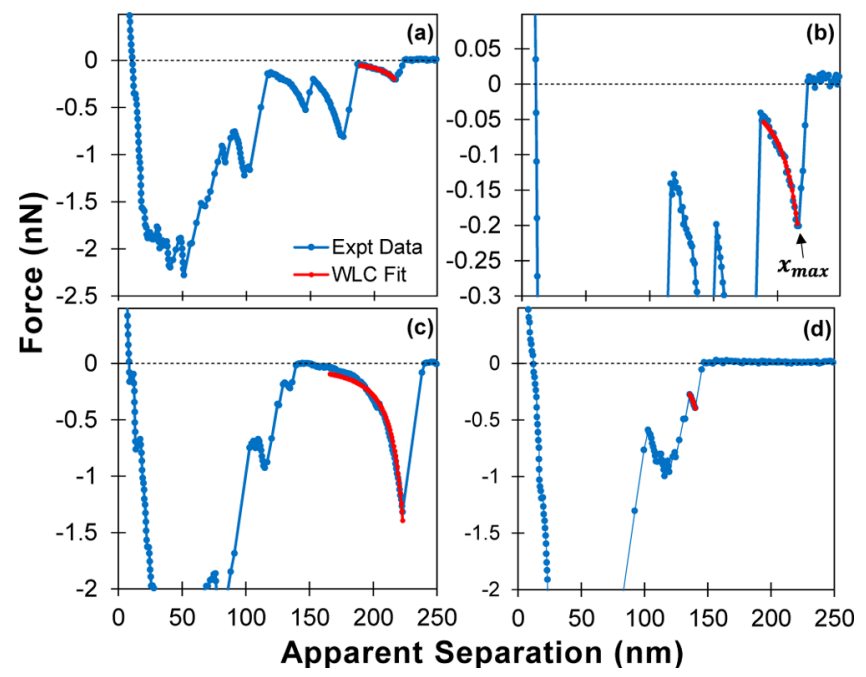

Figure 2. Typical force-distance curves from SMFS measurements of an $18.0 \mathrm{~nm}$ PDPA brush in $\mathrm{pH} 4.010 \mathrm{mM} \mathrm{KNO}_{3}$, shown in blue. The wormlike chain (WLC) fits are shown in red. (a) A typical example of an accepted curve with a low mean square error for the WLC fit and (b) showing the magnified final detachment event, with $x_{\max }$ identified. (c) An example of an excluded curve due to a low fitted value of persistence length; detachment of multiple chains with similar contour length. (d) An example of an excluded curve because the WLC fit was over fewer than 10 data points.

multiple chains with similar contour length being stretched simultaneously by the tip which cannot be accounted for by the WLC model. Figures $2 \mathrm{c}$ and $2 \mathrm{~d}$ show two typical examples of rejected curves. In Figure $2 c$, the magnitude of adhesion force is much greater than $-0.35 \mathrm{nN}$, while in Figure $2 \mathrm{~d}$ the WLC model can only be fitted to a limited number of measured data points $(<10)$ which is unsuitable.

To maximize the chance of adsorption at the end of the chain, the force measurements were performed at environmental conditions where the PDPA brush adopts its maximally swollen conformation, i.e., where the chains are most stretched. This increased the likelihood that the fitted contour length represented the true value of each individual chain. From our previous work this was shown to be between $\mathrm{pH} 4$ and $\mathrm{pH} 5$ of $10 \mathrm{mM}$ potassium nitrate electrolyte. ${ }^{15}$ At $\mathrm{pH} 4.0$, a total of 450 curves were collected with 75 of those curves accepted for final WLC statistical analysis (17\% acceptance). The percentage of accepted curves obtained at $\mathrm{pH} 5.0$ was similar at $15 \%$ with 128 curves analyzed from the 879 measured. At $\mathrm{pH} 5.5$, the swelling of the brush was reduced, and accordingly over $90 \%$ of the measured curves were unsuitable for WLC analysis (see Figure S1 showing that the relative penetration of the tip into the brush was on average substantially less at $\mathrm{pH} 5.5$ compared to $\mathrm{pH} 5.0$ and 4.0). The WLC fitting gave a distribution of persistence length and contour length values with further calculations providing additional information. These results are summarized in Table 2 for the $\mathrm{pH} 4$ and $\mathrm{pH} 5$ cases.

The results obtained at both conditions are very similar. This is not unexpected, since at $\mathrm{pH} 5.0$ and 4.0 PDPA brushes are highly swollen. ${ }^{15,20}$ The persistence length of the PDPA chains was found to be on average approximately $0.57 \pm 0.29 \mathrm{~nm}$. This value is greater than the monomer length and is close to the value recently reported for a poly(2-(dimethylamino)ethyl methacrylate) (PDMA) brush, ${ }^{70}$ the 2-dimethyl analogue of PDPA. The average chain contour length was $217 \pm 27 \mathrm{~nm}$. Overall, the chains were stretched to about $85 \%$ of their 
Table 2. SMFS Results for PDPA Brush at $\mathrm{pH} 4.0$ and $\mathrm{pH} 5.0,10 \mathrm{mM} \mathrm{KNO}_{3}$

\begin{tabular}{|c|c|c|c|c|c|c|}
\hline $\mathrm{pH}$ & $L_{\mathrm{p}}(\mathrm{nm})$ & $L_{\mathrm{c}}(\mathrm{nm})$ & $\%$ extension $\left(x_{\max } / L_{c} \times 100\right)$ & $M_{i}\left(\mathrm{~kg} \mathrm{~mol}^{-1}\right)$ & $\sigma\left(\mathrm{nm}^{-2}\right)$ & $\Sigma_{\text {good solvent }}$ \\
\hline 4.0 & $0.57 \pm 0.28$ & $219 \pm 29$ & $85 \pm 5$ & $158 \pm 20$ & $0.072 \pm 0.009$ & $13.2 \pm 1.3$ \\
\hline 5.0 & $0.57 \pm 0.30$ & $214 \pm 24$ & $85 \pm 5$ & $154 \pm 17$ & $0.074 \pm 0.008$ & $13.2 \pm 1.3$ \\
\hline mean & $0.57 \pm 0.29$ & $217 \pm 27$ & $85 \pm 5$ & $156 \pm 19$ & $0.073 \pm 0.009$ & $13.2 \pm 1.3$ \\
\hline
\end{tabular}

contour length, i.e., on average $x_{\max } \approx 0.85 L_{\mathrm{c}}$. That is, for the analyzed chain detachment events, on average the chains were stretched to approximately $85 \%$ of their length. Figure 3 shows

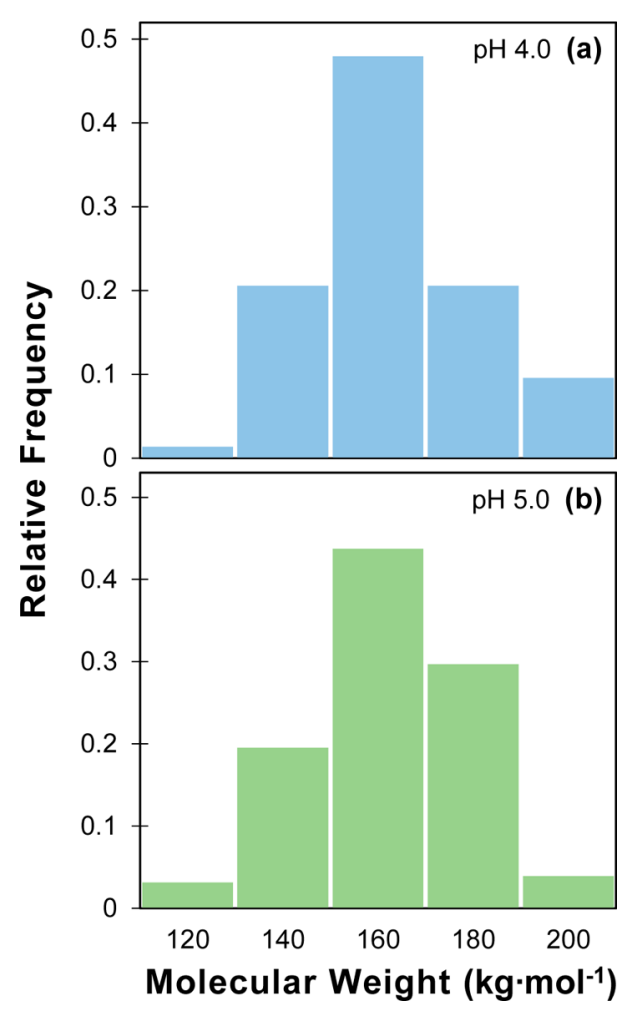

Figure 3. Molecular weight distribution histograms for the PDPA brush. The measurements were performed at (a) $\mathrm{pH} 4.0$ and (b) $\mathrm{pH}$ 5.0 in a background electrolyte of $10 \mathrm{mM}$ potassium nitrate.

the molecular weight distribution histograms for both the $\mathrm{pH}$ 4.0 and $\mathrm{pH} 5.0$ conditions. The distributions are similar, giving an average molecular weight of $156 \pm 19 \mathrm{~kg} \mathrm{~mol}^{-1}$. This value is an upper estimate of molecular weight because the SMFS analysis is biased toward longer chains in two ways: (1) there is an increased likelihood that these chains will adsorb to the AFM tip, and (2) our methodology only considers final detachment events as this is the situation most likely to involve the stretching of only one chain. Using eq 3, the grafting density was estimated to be approximately $0.073 \mathrm{~nm}^{-2}$, meaning that on average the distance between chains is $\sim 3.7$ $\mathrm{nm}$. Because the molecular weight is an upper estimate, the calculated grafting density is therefore a lower limit. The brushlike character of the polymer layer was confirmed via calculation of the reduced grafting density for a good solvent which was $\sim 13$, where values of $\Sigma>5$ confirm a brush. ${ }^{3}$

Influence of Ionic Strength. All the force measurements discussed in the next two sections are from a single PDPA brush and silica-colloid probe system. Figure 4 shows the most representative normalized force versus surface separation curves for the five different solution ionic strength values of potassium nitrate studied. Here, the approach and retraction curves are

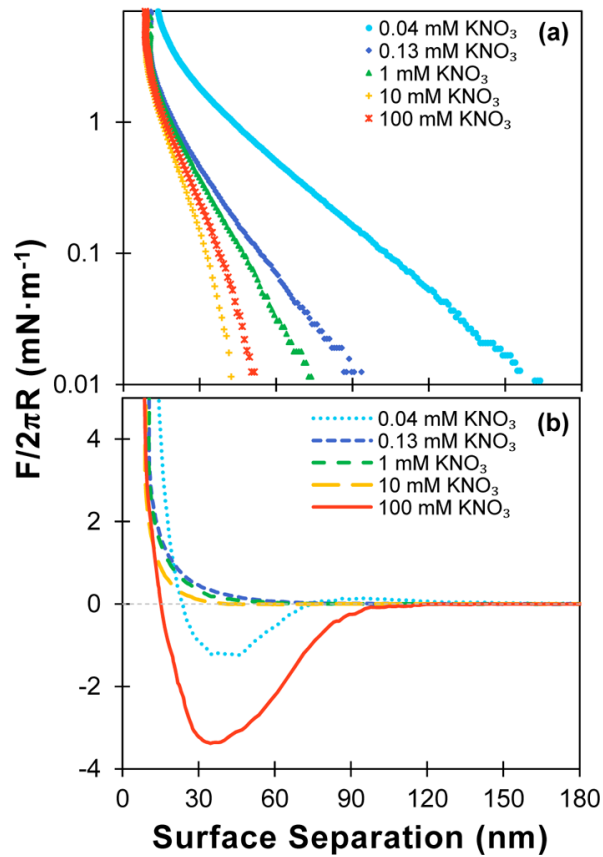

Figure 4. Most representative normalized force profiles on (a) approach and (b) retraction between an unmodified silica microsphere and a PDPA brush. Measurements were performed at five different ionic strengths of potassium nitrate electrolyte: $0.04,0.13,1,10$, and $100 \mathrm{mM}$, at a fixed $\mathrm{pH}$ of 4.5 . Note that the 0.04 and $0.13 \mathrm{mM}$ cases consist of 0.01 and $0.1 \mathrm{mM} \mathrm{KNO}_{3}$, respectively, with an additional $\sim 0.03 \mathrm{mM} \mathrm{HNO}_{3}$ from the $\mathrm{pH}$ adjustment. The normalized force upon approach of the colloid probe toward the brush is plotted on a logarithmic scale.

plotted separately with the force upon approach plotted on a logarithmic scale. Figure S2 presents the collated average force data. The main results of the AdG, MWC, and exponential fitting of the approach data are summarized in Table 3, with all of the fitted data presented in Table S1. As described in the Experimental section, these fits applied to charged polyelectrolyte brushes are approximations. Since the AdG and MWC theories do not consider the long-range electrostatic interactions present at low ionic strengths (at large $\kappa^{-1}$ values) and assume classical brush profiles (steplike and parabolic for AdG and MWC, respectively), the estimated brush thickness and grafting density values must be approached with caution. Indeed, the fits deviate considerably from the experimental force data for the low ionic strength cases (see Figure 5 for comparison of the quality of fits at 0.04 and $10 \mathrm{mM}$ potassium nitrate).

Starting with the $0.04 \mathrm{mM}$ case, upon approach of the colloid probe toward the PDPA brush the onset of the repulsive interaction occurs at about $160 \mathrm{~nm}$ (Figure 4a). This is greater than the estimated average contour length of the polymer chains of $\sim 130 \mathrm{~nm}$ (a scaled estimate based on the value of $L_{\mathrm{c}}$ obtained from the SMFS study), suggesting the presence of an electrostatic repulsive force. With increasing ionic strength up to $100 \mathrm{mM}$ the onset of the repulsive force moves to shorter 
Table 3. Results from the Alexander-de Gennes, Milner-Witten-Cates, and Exponential Fitting for the Influence of Potassium Nitrate on PDPA Brush Behavior

\begin{tabular}{|c|c|c|c|c|c|c|c|c|c|}
\hline \multirow[b]{2}{*}{ salt type } & \multirow[b]{2}{*}{$\begin{array}{l}\text { ionic } \\
\text { strength }^{a} \\
(\mathrm{mM})\end{array}$} & \multicolumn{2}{|c|}{ Alexander-de Gennes ${ }^{b}$} & \multicolumn{2}{|c|}{ Milner-Witten-Cates ${ }^{b}$} & \multicolumn{4}{|c|}{ exponential $^{b}$} \\
\hline & & $\begin{array}{l}\text { brush } \\
\text { thickness } \\
(\mathrm{nm})\end{array}$ & $\begin{array}{l}\text { grafting density } \\
\qquad\left(\mathrm{nm}^{-2}\right)\end{array}$ & $\begin{array}{l}\text { brush } \\
\text { thickness } \\
(\mathrm{nm})\end{array}$ & $\begin{array}{l}\text { grafting density } \\
\qquad\left(\mathrm{nm}^{-2}\right)\end{array}$ & $\begin{array}{l}\text { brush } \\
\text { thickness } \\
(\mathrm{nm})\end{array}$ & $\begin{array}{l}\text { brush } \\
\text { thickness } \\
\quad(\mathrm{nm})\end{array}$ & $\begin{array}{c}\text { decay length } \\
(\mathrm{nm})\end{array}$ & $\begin{array}{l}\text { theoretical Debye } \\
\text { length } \kappa^{-1}(\mathrm{~nm})\end{array}$ \\
\hline \multirow[t]{5}{*}{$\mathrm{KNO}_{3}$} & 0.04 & $118 \pm 4$ & $0.022 \pm 0.003$ & $149 \pm 4$ & $0.043 \pm 0.002$ & $144 \pm 2$ & $51 \pm 3$ & $23.0 \pm 0.3$ & 48 \\
\hline & 0.13 & $74 \pm 2$ & $0.023 \pm 0.004$ & $87 \pm 3$ & $0.034 \pm 0.003$ & $88 \pm 2$ & $40 \pm 1$ & $14.0 \pm 0.3$ & 27 \\
\hline & 1 & $69 \pm 3$ & $0.024 \pm 0.004$ & $75 \pm 1$ & $0.038 \pm 0.005$ & $76 \pm 2$ & & $12.1 \pm 0.3$ & 9.6 \\
\hline & 10 & $47 \pm 1$ & $0.033 \pm 0.006$ & $50 \pm 1$ & $0.047 \pm 0.007$ & $50 \pm 1$ & & $7.9 \pm 0.1$ & 3.0 \\
\hline & 100 & $49 \pm 3$ & $0.033 \pm 0.009$ & $58 \pm 2$ & $0.047 \pm 0.007$ & $56 \pm 1$ & & $8.9 \pm 0.2$ & 1.0 \\
\hline
\end{tabular}

$a_{0.04}$ and $0.13 \mathrm{mM}$ correspond to 0.01 and $0.1 \mathrm{mM} \mathrm{KNO}_{3}$ with $0.03 \mathrm{mM} \mathrm{HNO}_{3}$ from $\mathrm{pH}$ adjustment to $\mathrm{pH} 4.5$. ${ }^{b}$ Fitting was performed for all measured curves and presented values are the average values. ${ }^{c}$ Fitted with single exponential. ${ }^{d}$ Fitted with double exponential without error function (see Figure S3 and supporting explanations).

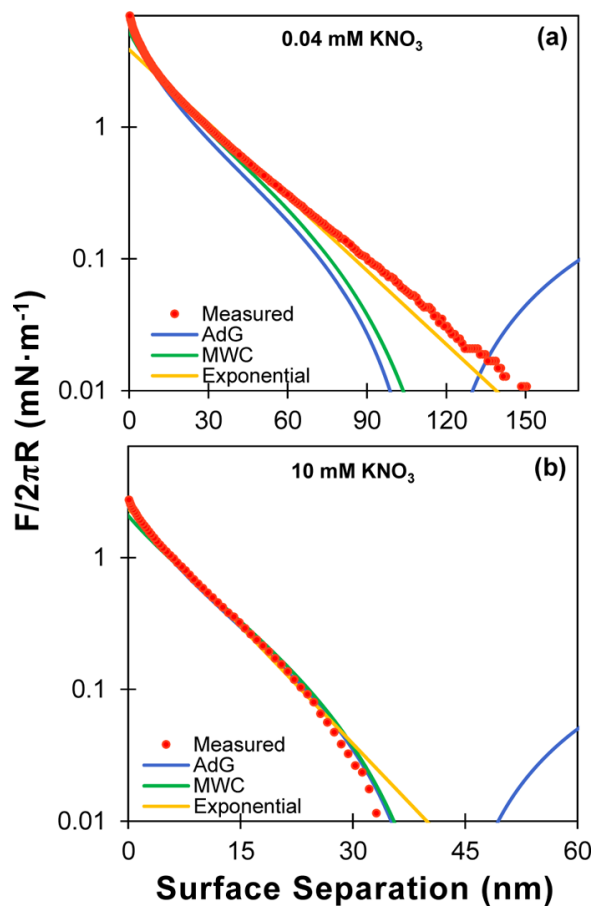

Figure 5. AdG, MWC, and exponential fitting of measured force data on a PDPA brush in (a) $0.04 \mathrm{mM} \mathrm{KNO}_{3}$ and (b) $10 \mathrm{mM} \mathrm{KNO}_{3}$. At low ionic strength the fits deviate considerably from the measured data, shown in red, suggested the repulsion is electrostatic in origin, while at higher ionic strength the fits reflect the measured data much more closely; a steric-dominated interaction.

separation distances and the shape of the force profile changes. This behavior can be the result of two essentially indistinguishable phenomena. First, as the solution ionic strength is raised, the Debye screening length becomes smaller and hence the range of electrostatic interactions decreases. Second, after reaching its maximum degree of ionization the weak polybasic brush enters the salted brush regime where brush thickness decreases with increasing added salt as screening effects are predominant. ${ }^{16,21}$ Consequently, physical contact between the brush and the colloid probe (steric interaction) will now occur at shorter separation distances.

In the 0.04 and $0.13 \mathrm{mM}$ cases, the PDPA brush is expected to be collapsed as hydrophobic polymer-polymer interactions are dominant because the brush possesses a low degree of charge. ${ }^{25}$ However, at these low ionic strength conditions, $\kappa^{-1}$ is large and so is the range of any electrostatic interactions in the system. As seen in Table 3, the theoretical $\kappa^{-1}$ values are greater than the fitted exponential decay lengths, which suggests that electrostatic interactions are a dominant factor and not physical compression of the brush. Intriguingly, this interaction is repulsive even though at $\mathrm{pH} 4.5$ the PDPA is expected to be positively charged and the silica colloid negative. It is unlikely that this repulsion would result from nitrate counterions associating with the weakly charged cationic polymer leading to charge inversion, with such behavior not predicted in weak polyelectrolyte brush theory. $^{21}$

An alternative explanation is that the repulsion arises from the negative charge of the underlying silica-coated substrate. However, attachment of the initiator moieties to the silanol groups on the silica surface should result in a decrease in the overall silica charge. Surface zeta potential measurements reveal that for the $0.04 \mathrm{mM}$ case and at $\mathrm{pH} 4.5$ the silica-coated substrate is highly negatively charged, with a measured surface zeta potential of $-43 \pm 3 \mathrm{mV}$. Amine-functionalization of the surface resulted in charge reversal with a surface zeta potential of $32 \pm 3 \mathrm{mV}$ measured. Upon conversion of the amine moieties to the initiator moieties, the measured surface zeta potential was negative again at $-29 \pm 2 \mathrm{mV}$. This value is less negative than that measured for the unmodified silica surface, suggesting that the charge is screened by the attachment of initiator layer, yet the surface remains negatively charged. For a PDPA brush surface of similar dry thickness and at the same electrolyte conditions the measured surface zeta potential was $-23 \pm 3 \mathrm{mV}$, confirming the strong influence of the silica surface charge. As the charge of the silica colloid is expected to be highly negative at $\mathrm{pH} 4.5$ and at low ionic strengths, ${ }^{71}$ the long-range repulsion in the AFM force measurements most likely results from an electrical double layer repulsion between the silica colloid and the brush surface. At much shorter separation distances, the repulsive force increases more steeply due to steric repulsion as the polymer chains become physically compressed by the colloid probe.

At 0.04 and $0.13 \mathrm{mM}$, the fitted brush thickness values correspond closely with the onset of the repulsive interaction (compare values in Table 3 with Figure 4a). However, because this interaction is predominantly electrostatic the brush thickness values are meaningless since electrostatic interactions are not accounted for within the AdG and MWC models. At these solution conditions, ellipsometric brush thickness measurements reveal that a PDPA brush is actually substantially collapsed. ${ }^{16}$ A better estimate of brush thickness was achieved by fitting the approach force profiles at low ionic strength as the summation of two exponential curves (see Table 3): one with a fixed decay length equal to the theoretical Debye screening 


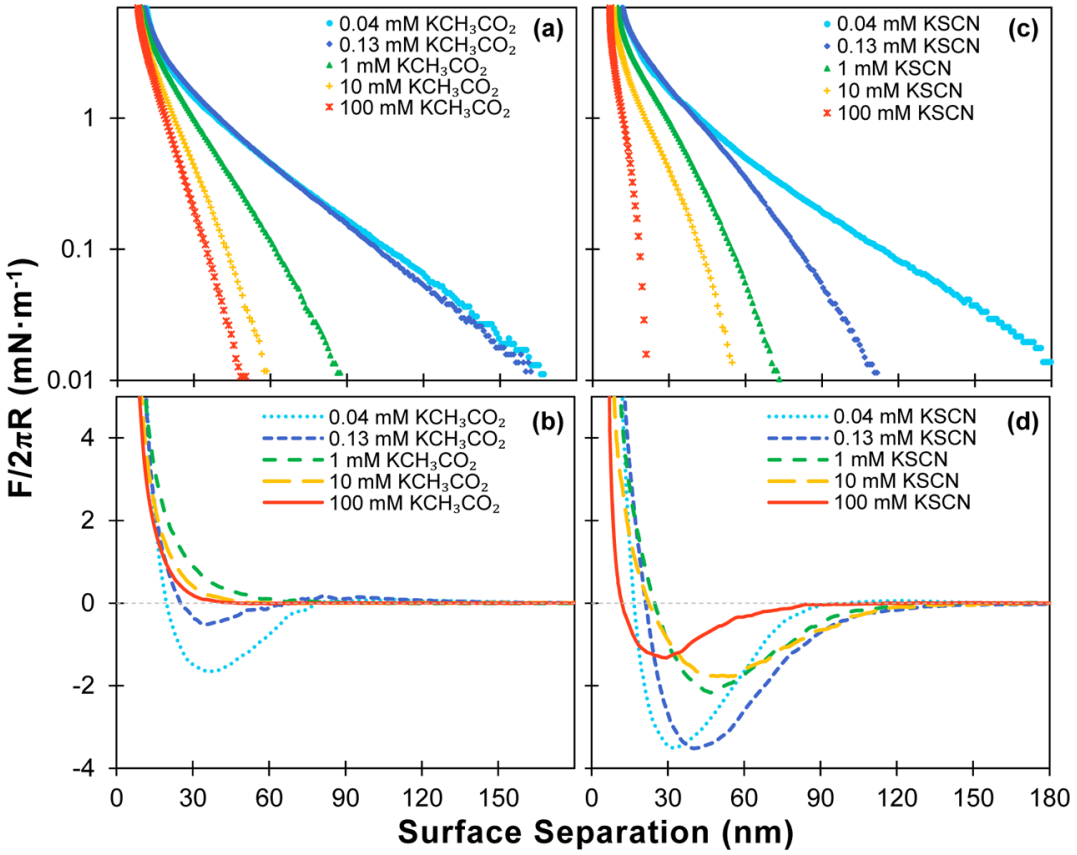

Figure 6. Most representative normalized force profiles on approach (upper plot, a and c) and retraction (lower plot, b and d) between an unmodified silica microsphere and a PDPA brush. Measurements were performed at five different ionic strengths of potassium acetate (left, a and $b$ ) and potassium thiocyanate (right, $\mathrm{c}$ and $\mathrm{d}$ ), $0.04,0.13,1,10$, and $100 \mathrm{mM}$, at controlled $\mathrm{pH}$ of 4.5 . Note that the 0.04 and $0.13 \mathrm{mM}$ cases consist of 0.01 and $0.1 \mathrm{mM}$, respectively, of the desired salt with an additional $0.03 \mathrm{mM}$ of salt from the $\mathrm{pH}$ adjustment. The normalized force upon approach of the colloid probe toward the brush is plotted on a logarithmic scale.

length and the other free, which changes to reflect the steric component of the approach curve (see Supporting Information for a description of this analysis, with examples shown in Figure S3).

At 1, 10, and $100 \mathrm{mM}$, the fitted exponential decay lengths are now greater than $\kappa^{-1}$, indicating that a steeper steric repulsion is now dominant over electrostatic repulsion, i.e., repulsion from compression of the brush. ${ }^{54}$ Previous work showed that at these higher ionic strengths a PDPA brush undergoes swelling and extends normal to the substrate, thus increasing the likelihood of a longer-range steric repulsion. ${ }^{16}$ The diminishing influence of electrostatics on the force curves as ionic strength is increased is also reflected in the improving quality of fit of the AdG and MWC models to the experimental data. At higher ionic strengths Zhulina et al. show that the unique polymer density profiles predicted for weak polyelectrolyte brushes at low to intermediate salt concentrations, characterized by a protruding edge of polymer density that decays slowly out to the bulk solution, transition to more parabolic-type profiles, closer to the assumed parabolic profile within the MWC model. ${ }^{32}$ The combination of the reduced influence of electrostatics and the theoretically predicted changes in polymer density profile at higher ionic strength means that the fitted brush thickness values obtained from especially the MWC modeling are more reasonable. Here, Table 3 shows that brush thickness decreases as expected for a PDPA brush in the salted brush regime. ${ }^{25}$ Modeling of the force curves at high ionic strength, therefore, also gives more accurate values of brush grafting density, with order of magnitude agreement with the value determined from the SMFS measurements, described earlier. The grafting density values obtained from the MWC modeling are greater (closer to the SMFS value) than those from the AdG modeling because a parabolic polymer density profile is more realistic than a steplike profile. The values for grafting density are lower than the expected value from the SMFS study, which perhaps reflects the lower density of PDPA chains toward the periphery of the brush rather than the grafting density at the substrate. ${ }^{13}$

Now we consider the retraction data shown in Figure 4b. For the $0.04 \mathrm{mM}$ case, the interaction is strongly adhesive. During approach of the colloid probe, at short separations the brush is physically compressed. At this point, attractive interactions between the weakly positively charged brush and the negative silica colloid occur after physical contact is made. These are most probably weak electrostatic or van der Waals attractive forces, but they may also be hydrophobic in origin. However, the silica colloid is strongly charged, ${ }^{71}$ so direct hydrophobic interactions are less likely. A hydrogen bonding interaction is also possible; however, the hydrogen bond accepting nitrogen site of the tertiary amine residues is sterically hindered by the isopropyl groups of the DPA monomers. During retraction of the probe, the attractive force reaches a maximum value (maximum adhesion of $\sim 1.2 \mathrm{~mJ} \mathrm{~m}^{-2}$ and overall $\sim 1600 \mathrm{~nJ}$ of energy dissipated) before returning to the baseline at a separation of approximately $65 \mathrm{~nm}$. Interestingly, the interaction between $\sim 65$ and $\sim 140 \mathrm{~nm}$ is slightly repulsive and closely overlays the approach force curve from $\sim 80 \mathrm{~nm}$ onward, all of which can be seen more clearly in the inset of Figure 1 and also in collated force curve data in Figure S2. Here we propose that at approximately $65 \mathrm{~nm}$ the PDPA chains physically detach from the silica colloid probe, and then the electrostatic force, discussed earlier, takes over and the silica colloid is repelled. We believe that this repulsive force observed during retraction between $\sim 65$ and $\sim 140 \mathrm{~nm}$ strongly supports the presence of a dominant electrostatic force present at low ionic strength, most probably resulting from the negative charge of the underlying silica substrate. 
From the $0.13 \mathrm{mM}$ case and up to $10 \mathrm{mM}$ potassium nitrate, the retraction curves directly overlay the approach curves, as shown in Figure S2. Now as the PDPA brush becomes increasingly more solvated, as shown by quartz crystal microbalance measurements in our previous work, ${ }^{16}$ the osmotic pressure associated with the adsorbed counterions and water molecules repels the silica colloid probe, preventing any attractive interactions between the brush and colloid. In $100 \mathrm{mM}$ potassium nitrate, the force during retraction is adhesive again. At this ionic strength and at $\mathrm{pH} 4.5$ the charge on the silica colloid is close to zero. ${ }^{71}$ Substantial screening of the electrostatic interactions means that hydrophobic interactions between the silica colloid and the hydrophobic PDPA brush are now more likely to cause the adhesive interaction observed. Here, the adhesion force is greater (maximum adhesion of $\sim 3.4 \mathrm{~mJ} \mathrm{~m}^{-2}$ and dissipation of $\sim 2400 \mathrm{~nJ}$, Figure S2) than at low potassium nitrate concentration, and this may suggest a different type of interaction, i.e., a hydrophobic force, or perhaps there were simply more adhesive contacts made between the colloid and brush. Similarly, an attractive force has also been observed by Drechsler et al. for the interaction of a silica colloid probe with a weakly basic poly(2-vinylpyridine) brush at $\mathrm{pH} 2.5$ (below the apparent brush $\mathrm{p} K_{\mathrm{a}}$ ) and in 100 $\mathrm{mM}$ potassium chloride. ${ }^{12}$

Influence of Anion Identity: Specific Anion Effects. Figure 6 presents the most representative normalized forcedistance curves measured for the potassium acetate (left) and thiocyanate (right) solutions. For the approach data, the behavior for both salts follows a similar trend to that of the potassium nitrate. Overall, as the ionic strength is increased from 0.04 up to $100 \mathrm{mM}$, the onset of the repulsive interaction moves to shorter distances. At 0.04 and $0.13 \mathrm{mM}$ potassium acetate and thiocyanate, the PDPA brush is expected to be collapsed with similarly low degrees of solvation; ${ }^{16}$ however, the repulsive interaction is much more long-ranged than this expected collapsed brush thickness. Comparing the fitted exponential decay lengths with the expected Debye lengths for the given solutions, presented in Table S1, it is clear that a longrange electrostatic force must be the primary cause of this repulsion at high separations. As is the case for nitrate, this behavior is a result of the unscreened underlying silica charge repelling the silica colloid. At smaller separations the force profiles are steeper due to the steric forces present during physical compression of the polymer brush by the probe. As seen for the nitrate case, by fitting the data at 0.04 and $0.13 \mathrm{mM}$ potassium acetate and thiocyanate with two separate exponential curves, one to account for the electrostatic interactions and the other for the steric interactions, more reasonable brush thickness values were obtained, reflecting the collapsed brush (see Table S1). At higher ionic strengths (1, 10, and $100 \mathrm{mM}$ ) the influence of electrostatics on the force profiles diminishes and the steric forces dominate, as reflected by the steepness of approach curves.

The most obvious anion-specific behavior is evident in the retraction data (compare Figure $4 \mathrm{~b}$ with Figures $6 \mathrm{~b}$ and $6 \mathrm{~d}$ ). For thiocyanate, at all ionic strengths studied the interaction is adhesive. Starting at $0.04 \mathrm{mM}$, a strong adhesive interaction is present for all salts studied. The similarity of this behavior is not unexpected since the brush is expected to be substantially collapsed at all these conditions. ${ }^{16}$ The adhesion most likely arises from an electrostatic or van der Waals interaction between the weakly charged brush and silica colloid. This is only possible after direct physical contact between the two surfaces which is experienced during approach as the brush is compressed. Again, like the nitrate data, the interaction becomes repulsive at larger separations (which is presented more clearly in Figure S2). After the PDPA chains detach from the probe (around 70-90 nm), repulsive electrical double layer forces dominate and the probe is repelled. At $0.13 \mathrm{mM}$ potassium acetate, very similar behavior is observed.

At higher concentrations of potassium acetate, like nitrate, the adhesive interactions disappear, and the force profiles become completely repulsive and directly overlay the approach data. Here, as the brush becomes more solvated, the associated osmotic forces repel the colloid probe, thus preventing direct contact between the brush and the silica colloid. However, a significant difference is observed at $100 \mathrm{mM}$ ionic strength. Unlike in nitrate, in potassium acetate the interaction remains repulsive. At this ionic strength the PDPA brush is expected to be more extended and solvated when in acetate than in nitrate, thus leading to higher osmotic forces in the acetate case. ${ }^{16}$ Moreover, acetate anions being kosmotropic in nature are more strongly hydrated than the mildly chaotropic nitrate anions. ${ }^{32,33}$

What is clearly visible in Figure $6 \mathrm{~d}$ is that at atl possium thiocyanate concentrations the force measured during retraction is adhesive. Unlike in the potassium acetate and nitrate solutions the PDPA brush remains substantially desolvated and collapsed over the entire range of ionic strengths of potassium thiocyanate. ${ }^{16}$ Consequently, at higher thiocyanate concentrations, any repulsive osmotic forces are weak and are not strong enough to prevent physical contact between the probe and brush, and therefore the attractive electrostatic or van der Waals forces prevail. Thiocyanate anions are weakly hydrated ${ }^{33,34}$ and consequently have been shown to preferentially interact with hydrophobic surfaces rather than water via weak dispersion interactions. ${ }^{37-40}$ Recently, thiocyanate has been shown to strongly interact with poly(2-methacryloyloxy)ethyl trimethylammonium chloride (PMETAC) brushes via proposed direct ion-pairing interactions with the positively charged quaternary ammonium monomer groups of the polymer, inducing brush collapse at higher thiocyanate concentrations. ${ }^{72}$ Interactions between thiocyanate and charged DPA monomer units would decrease the hydration of the bound anions and therefore result in a decrease in the solvation of the grafted chains. ${ }^{73}$ With increasing concentrations of thiocyanate the magnitude of the adhesive force decreases, with the adhesion values presented in Figure S2. Here, as the brush becomes more collapsed and desolvated with increasing thiocyanate concentration, ${ }^{16}$ fewer chains from the now flatter interface make contact with the silica colloid and hence fewer are stretched during retraction.

\section{CONCLUSIONS}

Normal force measurements between a silica colloid probe and a weakly basic PDPA brush have been used to investigate brush response to the varying solution ionic strength and the specific nature of the salt anions present in solution, with potassium acetate, nitrate, and thiocyanate studied. At low ionic strength and for all salts, electrostatic interactions are dominant. As the silica colloid approaches the brush surface, it is predominantly electrostatically repelled due to the unscreened charge of the underlying silica substrate, with a steric contribution at small separations as the brush is physically compressed. Upon retraction of the probe, attractive van der Waals or weak electrostatic forces result in an adhesive interaction between the colloid and the uncharged hydrophobic brush. At increased 
ionic strengths of kosmotropic potassium acetate and mildly chaotropic potassium nitrate, the brush swells by solvent uptake, and the associated high osmotic forces prevent physical contact between the two surfaces. Now the interaction over the entire approach-retraction cycle is repulsive. In $100 \mathrm{mM}$ potassium nitrate, however, the decreased solvation of the PDPA brush together with the lower charge on the silica colloid causes the interaction to be attractive once more. The most dramatic specific anion effects are observed in the presence of the strongly chaotropic thiocyanate anions. The poorly solvated thiocyanate anions partition toward the hydrophobic PDPA brush by dispersion forces, and as a consequence the brush is collapsed and desolvated. Now, at all thiocyanate concentrations, the interaction of the hydrophobic brush with the silica colloid is adhesive.

Additional single-molecule force spectroscopy measurements using a sharp AFM tip have allowed a number of fundamental characteristics of the brush to be quantified. The persistence and contour lengths and molecular weight of the brush chains were determined. This was achieved by modeling hundreds of individual chain stretching events, using the WLC model, measured between a sharp tip and an extended and solvated PDPA brush. We show that studying a highly swollen brush is very important for accurate measurements to be made. This is a nondestructive and physical measurement technique. Significantly, this procedure allowed the brush grafting density to be calculated. These values were of similar order to those obtained from MWC modeling of the approach curves from the colloid probe measurements. Application of MWC theory, originally developed for uncharged brushes (as well AdG theory), was successful at conditions where the influence of electrostatic interactions on the measured force profiles was substantially diminished (i.e., at higher ionic strengths).

\section{ASSOCIATED CONTENT}

\section{S Supporting Information}

The Supporting Information is available free of charge on the ACS Publications website at DOI: 10.1021/acs.macromol.5b02656.

Details of synthetic protocols, descriptions of AdG and MWC brush theories and exponential modeling, relative penetration of AFM tip into PDPA brush during

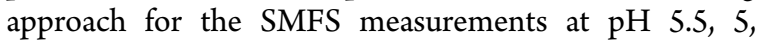
and 4 , collated average force data, tabulated results from all AdG, MWC and exponential fitting for nitrate, acetate and thiocyanate cases and detailed explanation of doubleexponential fitting at low ionic strengths with graphic examples (PDF)

\section{AUTHOR INFORMATION}

\section{Corresponding Author}

*(E.J.W.) E-mail erica.wanless@newcastle.edu.au, phone +61 2 40339355.

\section{Notes}

The authors declare no competing financial interest.

\section{ACKNOWLEDGMENTS}

C. Thomas is thanked for initial AFM measurements. This research was supported by the Australian Research Council (DP110100041).

\section{REFERENCES}

(1) Cohen Stuart, M. A.; Huck, W. T. S.; Genzer, J.; Muller, M.; Ober, C.; Stamm, M.; Sukhorukov, G. B.; Szleifer, I.; Tsukruk, V. V.; Urban, M.; Winnik, F.; Zauscher, S.; Luzinov, I.; Minko, S. Emerging Applications of Stimuli-Responsive Polymer Materials. Nat. Mater. 2010, 9, 101-113.

(2) Krishnamoorthy, M.; Hakobyan, S.; Ramstedt, M.; Gautrot, J. E. Surface-Initiated Polymer Brushes in the Biomedical Field: Applications in Membrane Science, Biosensing, Cell Culture, Regenerative Medicine and Antibacterial Coatings. Chem. Rev. 2014, 114, 1097611026.

(3) Brittain, W. J.; Minko, S. A Structural Definition of Polymer Brushes. J. Polym. Sci., Part A: Polym. Chem. 2007, 45, 3505-3512.

(4) Dobrynin, A. V.; Rubinstein, M. Theory of Polyelectrolytes in Solutions and at Surfaces. Prog. Polym. Sci. 2005, 30, 1049-1118.

(5) Jia, H.; Wildes, A.; Titmuss, S. Structure of $\mathrm{pH}$-Responsive Polymer Brushes Grown at the Gold-Water Interface: Dependence on Grafting Density and Temperature. Macromolecules 2012, 45, 305312.

(6) Yenice, Z.; Schön, S.; Bildirir, H.; Genzer, J.; von Klitzing, R. Thermoresponsive PDMAEMA Brushes: Effect of Gold Nanoparticle Deposition. J. Phys. Chem. B 2015, 119, 10348-10358.

(7) Thomas, M.; Gajda, M.; Amiri Naini, C.; Franzka, S.; Ulbricht, M.; Hartmann, N. Poly(N,N-dimethylaminoethyl-methacrylate) Brushes: pH-Dependent Switching Kinetics of a Surface-Grafted Thermoresponsive Polyelectrolyte. Langmuir 2015, 31, 13426-13432.

(8) de Vos, W. M.; Biesheuvel, P. M.; de Keizer, A.; Kleijn, J. M.; Cohen Stuart, M. A. Adsorption of the Protein Bovine Serum Albumin in a Planar Poly(acrylic acid) Brush Layer As Measured by Optical Reflectometry. Langmuir 2008, 24, 6575-6584.

(9) Hadjesfandiari, N.; Yu, K.; Mei, Y.; Kizhakkedathu, J. N. Polymer Brush-Based Approaches for the Development of Infection-Resistant Surfaces. J. Mater. Chem. B 2014, 2, 4968-4978.

(10) Bronder, T. S.; Poghossian, A.; Scheja, S.; Wu, C.; Keusgen, M.; Mewes, D.; Schöning, M. J. DNA Immobilization and Hybridization Detection by the Intrinsic Molecular Charge Using Capacitive FieldEffect Sensors Modified with a Charged Weak Polyelectrolyte Layer. ACS Appl. Mater. Interfaces 2015, 7, 20068-20075.

(11) Drechsler, A.; Synytska, A.; Uhlmann, P.; Elmahdy, M. M.; Stamm, M.; Kremer, F. Interaction Forces between Microsized Silica Particles and Weak Polyelectrolyte Brushes at Varying $\mathrm{pH}$ and Salt Concentration. Langmuir 2010, 26, 6400-6410.

(12) Drechsler, A.; Synytska, A.; Uhlmann, P.; Stamm, M.; Kremer, F. Tuning the Adhesion of Silica Microparticles to a Poly (2-vinyl pyridine) Brush: An AFM Force Measurement Study. Langmuir 2012, 28, 15555-15565.

(13) Elmahdy, M.; Drechsler, A.; Bittrich, E.; Uhlmann, P.; Stamm, M. Interactions between Silica Particles and Poly(2-vinylpyridine) Brushes in Aqueous Solutions of Monovalent and Multivalent Salts. Colloid Polym. Sci. 2014, 292, 1999-2012.

(14) Dunderdale, G. J.; Urata, C.; Miranda, D. F.; Hozumi, A. LargeScale and Environmentally Friendly Synthesis of pH-Responsive OilRepellent Polymer Brush Surfaces under Ambient Conditions. ACS Appl. Mater. Interfaces 2014, 6, 11864-11868.

(15) Willott, J. D.; Humphreys, B. A.; Murdoch, T. J.; Edmondson, S.; Webber, G. B.; Wanless, E. J. Hydrophobic Effects within the Dynamic pH Response of Polybasic Tertiary Amine Methacrylate Brushes. Phys. Chem. Chem. Phys. 2015, 17, 3880-3890.

(16) Willott, J. D.; Murdoch, T. J.; Humphreys, B. A.; Edmondson, S.; Wanless, E. J.; Webber, G. B. Anion-Specific Effects on the Behavior of pH-Sensitive Polybasic Brushes. Langmuir 2015, 31, 3707-3717.

(17) Willott, J. D.; Murdoch, T. J.; Humphreys, B. A.; Edmondson, S.; Webber, G. B.; Wanless, E. J. Critical Salt Effects in the Swelling Behavior of a Weak Polybasic Brush. Langmuir 2014, 30, 1827-1836.

(18) Topham, P. D.; Glidle, A.; Toolan, D. T. W.; Weir, M. P.; Skoda, M. W. A.; Barker, R.; Howse, J. R. The Relationship between Charge Density and Polyelectrolyte Brush Profile Using Simultaneous 
Neutron Reflectivity and In Situ Attenuated Total Internal Reflection FTIR. Langmuir 2013, 29, 6068-6076.

(19) Stratakis, E.; Mateescu, A.; Barberoglou, M.; Vamvakaki, M.; Fotakis, C.; Anastasiadis, S. H. From Superhydrophobicity and Water Repellency to Superhydrophilicity: Smart Polymer-Functionalized Surfaces. Chem. Commun. 2010, 46, 4136-4138.

(20) Fielding, L. A.; Edmondson, S.; Armes, S. P. Synthesis of pHResponsive Tertiary Amine Methacrylate Polymer Brushes and Their Response to Acidic Vapour. J. Mater. Chem. 2011, 21, 11773-11780. (21) Zhulina, E. B.; Borisov, O. V. Poisson-Boltzmann Theory of pH-Sensitive (Annealing) Polyelectrolyte Brush. Langmuir 2011, 27, 10615-10633.

(22) Nap, R.; Gong, P.; Szleifer, I. Weak Polyelectrolytes Tethered to Surfaces: Effect of Geometry, Acid-Base Equilibrium and Electrical Permittivity. J. Polym. Sci., Part B: Polym. Phys. 2006, 44, 2638-2662.

(23) Nap, R.; Tagliazucchi, M.; Szleifer, I. Born Energy, Acid-Base Equilibrium, Structure and Interactions of End-Grafted Weak Polyelectrolyte Layers. J. Chem. Phys. 2014, 140, 024910.

(24) Israëls, R.; Leermakers, F. A. M.; Fleer, G. J. On the Theory of Grafted Weak Polyacids. Macromolecules 1994, 27, 3087-3093.

(25) Zhulina, E. B.; Birshtein, T. M.; Borisov, O. V. Theory of Ionizable Polymer Brushes. Macromolecules 1995, 28, 1491-1499.

(26) Lyatskaya, Y. V.; Leermakers, F. A. M.; Fleer, G. J.; Zhulina, E. B.; Birshtein, T. M. Analytical Self-Consistent-Field Model of Weak Polyacid Brushes. Macromolecules 1995, 28, 3562-3569.

(27) Currie, E. P. K.; Sieval, A. B.; Fleer, G. J.; Cohen Stuart, M. A. Polyacrylic Acid Brushes: Surface Pressure and Salt-Induced Swelling. Langmuir 2000, 16, 8324-8333.

(28) Biesalski, M.; Johannsmann, D.; Rühe, J. Synthesis and Swelling Behavior of a Weak Polyacid Brush. J. Chem. Phys. 2002, 117, 4988.

(29) Zhang, H.; Rühe, J. Swelling of Poly(methacrylic acid) Brushes: Influence of Monovalent Salts in the Environment. Macromolecules 2005, 38, 4855-4860.

(30) Wu, T.; Gong, P.; Szleifer, I.; Vlček, P.; Šubr, V.; Genzer, J. Behavior of Surface-Anchored Poly(acrylic acid) Brushes with Grafting Density Gradients on Solid Substrates: 1. Experiment. Macromolecules 2007, 40, 8756-8764.

(31) Gibb, B. C. Supramolecular Assembly and Binding in Aqueous Solution: Useful Tips Regarding the Hofmeister and Hydrophobic Effects. Isr. J. Chem. 2011, 51, 798-806.

(32) Lo Nostro, P.; Ninham, B. W. Hofmeister Phenomena: An Update on Ion Specificity in Biology. Chem. Rev. 2012, 112, 22862322.

(33) Marcus, Y. Effect of Ions on the Structure of Water: Structure Making and Breaking. Chem. Rev. 2009, 109, 1346-1370.

(34) Mason, P. E.; Neilson, G. W.; Dempsey, C. E.; Barnes, A. C.; Cruickshank, J. M. The Hydration Structure of Guanidinium and Thiocyanate Ions: Implications for Protein Stability in Aqueous Solution. Proc. Natl. Acad. Sci. U. S. A. 2003, 100, 4557-4561.

(35) Viswanath, P.; Motschmann, H. Oriented Thiocyanate Anions at the Air-Electrolyte Interface and Its Implications on Interfacial Water - A Vibrational Sum Frequency Spectroscopy Study. J. Phys. Chem. C 2007, 111, 4484-4486.

(36) Pegram, L. M.; Record, M. T. Hofmeister Salt Effect on Surface Tension Arise from Partitioning of Anions and Cations between Bulk Water and the Air-Water Interface. J. Phys. Chem. B 2007, 111, 54115417.

(37) Boström, M.; Williams, D. R. M.; Ninham, B. W. Specific Ion Effects: Why the Properties of Lysozyme in Salt Solutions Follow a Hofmeister Series. Biophys. J. 2003, 85, 686-694.

(38) Swann, J. M. G.; Bras, W.; Topham, P. D.; Howse, J. R.; Ryan, A. Effect of the Hofmeister Anions upon the Swelling of a SelfAssembled pH-Responsive Hydrogel. Langmuir 2010, 26, 1019110197.

(39) Rembert, K. B.; Paterová, J.; Heyda, J.; Hilty, C.; Jungwirth, P.; Cremer, P. S. Molecular Mechanisms of Ion-Specific Effects on Proteins. J. Am. Chem. Soc. 2012, 134, 10039-10046.

(40) Collins, K. D. Sticky Ions in Biological Systems. Proc. Natl. Acad. Sci. U. S. A. 1995, 92, 5553-5557.
(41) Pegram, L. M.; Record, M. T. Thermodynamic Origin of Hofmeister Ion Effects. J. Phys. Chem. B 2008, 112, 9428-9436.

(42) Hayashi, S.; Abe, T.; Higashi, N.; Niwa, M.; Kurihara, K. Polyelectrolyte Brush Layers Studied by Surface Forces Measurement: Dependence on $\mathrm{pH}$ and Salt Concentrations and Scaling. Langmuir 2002, 18, 3932-3944.

(43) Balastre, M.; Li, F.; Schorr, P.; Yang, J.; Mays, J. W.; Tirrell, M. V. A Study of Polyelectrolyte Brushes Formed from Adsorption of Amphiphilic Diblock Copolymers Using the Surface Forces Apparatus. Macromolecules 2002, 35, 9480-9486.

(44) Liberelle, B.; Giasson, S. Friction and Normal Interaction Forces between Irreversibly Attached Weakly Charged Polymer Brushes. Langmuir 2008, 24, 1550-1559.

(45) Raviv, U.; Giasson, S.; Kampf, N.; Gohy, J. F.; Jérôme, R.; Klein, J. Normal and Frictional Forces between Surfaces Bearing Polyelectrolyte Brushes. Langmuir 2008, 24, 8678-8687.

(46) Dunlop, I. E.; Briscoe, W. H.; Titmuss, S.; Jacobs, R. M. J.; Osborne, V. L.; Edmondson, S.; Huck, W. T. S.; Klein, J. Direct Measurement of Normal and Shear Forces between Surface-Grown Polyelectrolyte Layers. J. Phys. Chem. B 2009, 113, 3947-3956.

(47) Elmahdy, M. M.; Synytska, A.; Drechsler, A.; Gutsche, C.; Uhlmann, P.; Stamm, M.; Kremer, F. Forces of Interaction between Poly(2-vinylpyridine) Brushes As Measured by Optical Tweezers. Macromolecules 2009, 42, 9096-9102.

(48) Dominguez-Espinosa, G.; Synytska, A.; Drechsler, A.; Gutsche, C.; Kegler, K.; Uhlmann, P.; Stamm, M.; Kremer, F. Optical Tweezers to Measure the Interaction Between Poly(acrylic acid) Brushes. Polymer 2008, 49, 4802-4807.

(49) Murakami, D.; Takenaka, A.; Kobayashi, M.; Jinnai, H.; Takahara, A. Measurement of the Electrostatic Interaction between Polyelectrolyte Brush Surfaces by Optical Tweezers. Langmuir 2013, 29, 16093-16097.

(50) Farhan, T.; Azzaroni, O.; Huck, W. T. S. AFM Study of Cationically Charged Polymer Brushes: Switching Between Soft and Hard Matter. Soft Matter 2005, 1, 66-68.

(51) Parnell, A. J.; Martin, S. J.; Jones, R. A. L.; Vasilev, C.; Crook, C. J.; Ryan, A. J. Direct Visualization of the Real Time Swelling and Collapse of a Poly(methacrylic acid) Brush Using Atomic Force Microscopy. Soft Matter 2009, 5, 296-299.

(52) Raftari, M.; Zhang, Z. J.; Carter, S. R.; Leggett, G. J.; Geoghegan, M. Nanoscale Contact Mechanics between Two Grafted Polyelectrolyte Surfaces. Macromolecules 2015, 48, 6272-6279.

(53) Block, S.; Helm, C. A. Conformation of Poly(styrene sulfonate) Layers Physisorbed from High Salt Solution Studied by Force Measurements on Two Different Length Scales. J. Phys. Chem. B 2008, 112, 9318-9327.

(54) Nordgren, N.; Rutland, M. W. Tunable Nanolubrication between Dual-Responsive Polyionic Grafts. Nano Lett. 2009, 9, 2984-2990.

(55) Spruijt, E.; Cohen Stuart, M. A.; van der Gucht, J. Dynamic Force Spectroscopy of Oppositely Charged Polyelectrolyte Brushes. Macromolecules 2010, 43, 1543-1550.

(56) Cuellar, J. L.; Llarena, I.; Iturri, J. J.; Donath, E.; Moya, S. E. A Novel Approach for Measuring the Intrinsic Nanoscale Thickness of Polymer Brushes by means of Atomic Force Microscopy: Application of a Compressible Fluid Model. Nanoscale 2013, 5, 11679-11685.

(57) Ralston, J.; Larson, I.; Rutland, M. W.; Feiler, A. A.; Kleijn, M. Atomic Force Microscopy and Direct Surface Force Measurements (IUPAC Technical Report). Pure Appl. Chem. 2005, 77, 2149-2170.

(58) Butt, H. J.; Cappella, B.; Kappl, M. Force Measurements with the Atomic Force Microscope: Technique, Interpretation and Applications. Surf. Sci. Rep. 2005, 59, 1-152.

(59) Yamamoto, S.; Tsujii, Y.; Fukuda, T. Atomic Force Microscopic Study of Stretching a Single Polymer Chain in a Polymer Brush. Macromolecules 2000, 33, 5995-5998.

(60) Goodman, D.; Kizhakkedathu, J. N.; Brooks, D. E. Evaluation of an Atomic Force Microscopy Pull-Off Method for Measuring Molecular Weight and Polydispersity of Polymer Brushes: Effect of Grafting Density. Langmuir 2004, 20, 6238-6245. 
(61) Flory, P. J. Statistical Mechanics of Chain Molecules; Interscience: 1969.

(62) Yu, Y.; Kieviet, B. D.; Liu, F.; Siretanu, I.; Kutnyanszky, E.; Vancso, G. J.; de Beer, S. Stretching of Collapsed Polymers Causes an Enhanced Dissipative Response of PNIPAM Brushes Near Their LCST. Soft Matter 2015, 11, 8508-8516.

(63) de Gennes, P. G. Conformations of Polymers Attached to an Interface. Macromolecules 1980, 13, 1069-1075.

(64) Milner, S. T.; Witten, T. A.; Cates, M. E. Theory of the Grafted Polymer Brush. Macromolecules 1988, 21, 2610-2619.

(65) O'Shea, S. J.; Welland, M. E.; Rayment, T. An Atomic Force Microscope Study of Grafted Polymers on Mica. Langmuir 1993, 9, $1826-1835$.

(66) Patil, R. R.; Turgman-Cohen, S.; Šrogl, J.; Kiserow, D.; Genzer, J. On-Demand Degrafting and the Study of Molecular Weight and Grafting Density of Poly(methyl methacrylate) Brushes on Flat Silica Substrates. Langmuir 2015, 31, 2372-2381.

(67) Turgman-Cohen, S.; Genzer, J. Computer Simulation of Concurrent Bulk- and Surface-Initiated Living Polymerization. Macromolecules 2012, 45, 2128-2137.

(68) Al-Maawali, S.; Bemis, J. E.; Akhremitchev, B. B.; Leecharoen, R.; Janesko, B. G.; Walker, G. C. Study of the Polydispersity of Grafted Poly(dimethylsiloxane) Surfaces Using Single-Molecule Atomic Force Microscopy. J. Phys. Chem. B 2001, 105, 3965-3971.

(69) Parnell, A. J.; Martin, S. J.; Dang, C. C.; Geoghegan, M.; Jones, R. A. L.; Crook, C. J.; Howse, J. R.; Ryan, A. J. Synthesis, Characterization and Swelling Behaviour of Poly(methacrylic acid) Brushes Synthesized Using Atom Transfer Radical Polymerization. Polymer 2009, 50, 1005-1014.

(70) Al-Baradi, A.; Tomlinson, M. R.; Zhang, Z. J.; Geoghegan, M. Determination of the Molar Mass of Surface-Grafted Weak Polyelectrolyte Brushes Using Force Spectroscopy. Polymer 2015, 67, 111-117.

(71) Franks, G. V. Zeta Potentials and Yield Stresses of Silica Suspensions in Concentrated Monovalent Electrolytes: Isoelectric Point Shift and Additional Attraction. J. Colloid Interface Sci. 2002, 249, $44-51$.

(72) Kou, R.; Zhang, J.; Wang, T.; Liu, G. Interactions between Polyelectrolyte Brushes and Hofmeister Ions: Chaotropes versus Kosmotropes. Langmuir 2015, 31, 10461-10468.

(73) dos Santos, A. P.; Diehl, A.; Levin, Y. Surface Tensions, Surface Potentials, and the Hofmeister Series of Electrolyte Solutions. Langmuir 2010, 26, 10778-10783. 